\title{
Economic costs of recorded reasons for cow mortality and culling in a pasture-based dairy industry
}

\author{
J. I. Kerslake, ${ }^{* 1}$ P. R. Amer, ${ }^{\star}$ P. L. O’Neill, ${ }^{*}$ S. L. Wong, ${ }^{*}$ J. R. Roche,† and C. V. C. Phyn† \\ *AbacusBio Limited, Dunedin, 9058, New Zealand \\ †DairyNZ Limited, Hamilton, 3240, New Zealand
}

\begin{abstract}
The objective of this study was to determine the economic costs associated with different reasons for cow culling or on-farm mortality in a pasture-based seasonal system. A bioeconomic model was developed to quantify costs associated with the different farmerrecorded reasons and timing of cow wastage. The model accounted for the parity and stage of lactation at which the cows were removed as well as the consequent effect on the replacement rate and average age structure of the herd. The costs and benefits associated with the change were quantified, including animal replacement cost, cull salvage value, milk production loss, and the profitability of altered genetic merit based on industry genetic trends for each parity. The total cost of cow wastage was estimated to be NZ $\$ 23,628 / 100$ cows per year (NZ $\$ 1=\mathrm{US} \$ 0.69)$ in a pasture-based system. Of this total cost, NZ $\$ 14,300 / 100$ cows worth of removals were for nonpregnancy and unknown reasons, and another NZ $\$ 3,631 / 100$ cows was attributed to low milk production, mastitis, and udder problems. The total cost for cow removals due to farmer-recorded biological reasons (excluding unknown, production, and management-related causes) was estimated to be NZ $\$ 13,632 / 100$ cows per year. Of this cost, an estimated NZ $\$ 10,286 / 100$ cows was attributed to nonpregnancy, mastitis, udder problems, calving trouble, and injury or accident. There is a strong economic case for the pasture-based dairy industries to invest in genetic, herd health, and production management research focused on reducing animal wastage due to reproductive failure, mastitis, udder problems, injuries or accidents, and calving difficulties.
\end{abstract}

Key words: economic cost, dairy cow culling, pasturebased dairy industry

Received May 7, 2017.

Accepted October 18, 2017.

${ }^{1}$ Corresponding author: jkerslake@abacusbio.co.nz

\section{INTRODUCTION}

To meet the growing demand for dairy products worldwide, an increase in milk production per cow has been driven through genetic selection for greater production efficiency and improvements in nutrition and management (Rauw et al., 1998; Oltenacu and Broom, 2010). Although this has been beneficial in terms of milk production, there are growing concerns that continual genetic selection for high production efficiency in dairy cows is increasing the risk of behavioral, physiological, and immunological problems (Rauw et al., 1998) and, consequently, the risk of health disorders, premature culling, or death on farm (Beaudeau et al., 2000; Mulligan and Doherty, 2008). Thus, genetic, nutrition, and management research to improve the lifetime productivity of dairy cows is becoming a focus worldwide (Beaudeau et al., 1996; Mulligan et al., 2006; Pritchard et al., 2012). Expected benefits from improving lifetime productivity include more productive dairy herds due to improvement in average age and therefore lifetime milk production (Horan et al., 2005; Walsh et al., 2007), reductions in costs due to requiring fewer replacement animals (Bach, 2011; Mohd Nor et al., 2015), and a reduction in costs due to fewer health treatments and performance-limiting health disorders (Beaudeau et al., 1995; Fourichon et al., 1999). Healthier and more robust cows are also easier and less labor intensive to manage, with improvements in the length of cow productive life reflecting positively on animal welfare (Oltenacu and Algers, 2005; de Vries et al., 2014), the environment (Beukes et al., 2010), and, consequently, the general public and consumer perception of dairy farming.

There is, however, a current lack of detailed understanding of why or when cows are exiting herds in pasture-based dairy industries. This gap in knowledge means that we cannot track survival or mortality trends over time, making it difficult to target research at the most important issues. The objective of this work was to understand when cows are exiting herds and to determine the economic costs associated with differ- 
Table 1. Total number of cows assigned to each fate reason group for reproductive, health, other, physical, performance, management, and unknown reasons

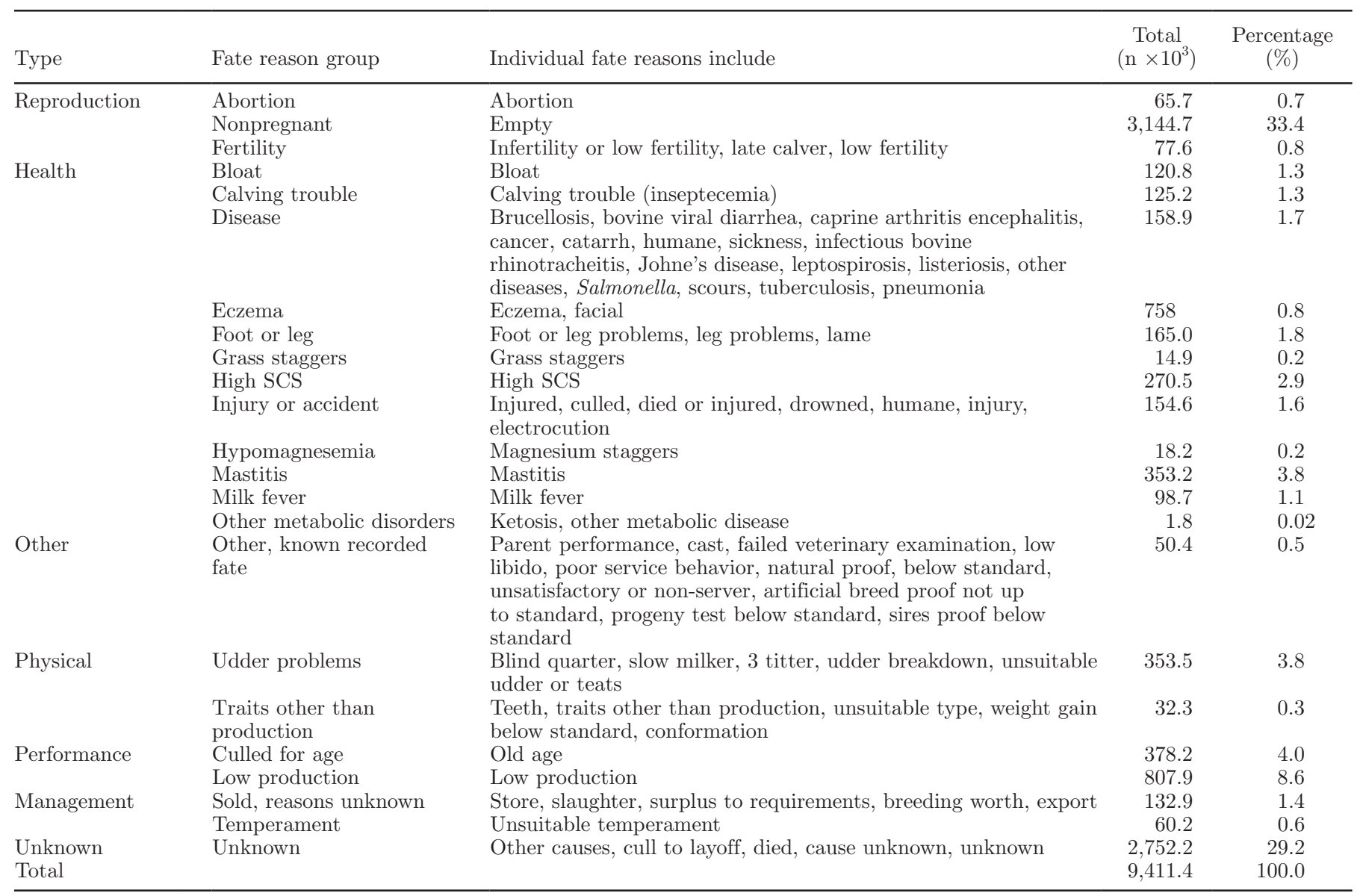

ent reasons for cow wastage, due to culling or on-farm mortality, in a pasture-based seasonal dairy industry.

\section{MATERIALS AND METHODS}

\section{Data Source and Management}

The New Zealand dairy industry national animal data set $(\mathrm{n}=46,520,335)$ was filtered to obtain records between 1990 and 2013 for cows 2 yr or older with a fate type of died on farm ( $\mathrm{n}=2,518,224)$, culled $(\mathrm{n}=$ $13,875,888)$, or sent to slaughter $(\mathrm{n}=5,284)$. Cow records missing a fate reason or fate date $(\mathrm{n}=6,988,011)$ were removed, leaving 9,411,385 records, which were aggregated into 23 groups of similar fate reasons (Table 1). These data were then cross-classified in 3 different ways. The first involved describing the overall proportion of different farmer-recorded reasons contributing to cow wastage, including biological (reproductive, health, other, and physical reasons), performance and management, and unknown reasons (Table 1). The second involved describing the proportion of recorded reasons by parity (Table 2). Because calving is seasonal in pasture-based systems, parity (values ranging from 1 to $7+$ ) was quantifthe calving year before the wastage event minus the year of birth. The third involved describing the proportion of recorded reasons by stage of lactation. Stage of lactation was defined as the recorded fate date minus last calving date (beginning $=0-30$ DIM; early $=30-90$ DIM; mid $=90-200$ DIM; late $=$ 200-330 DIM; extreme $=330+$ DIM).

\section{Quantifying Costs of Different Reasons for Cow Wastage}

A bioeconomic model was developed to quantify costs associated with the different reasons and timing for wastage. The model first considered the parity that cows exit and the consequent effect this had on the replacement rate and average age structure of the herd. The model then considered the effect this had on replacement cost, carcass salvage value, milk produc- 
Table 2. Total number of cows for each fate cause for parities 1 to $5+^{1}$

\begin{tabular}{|c|c|c|c|c|c|c|c|c|c|c|}
\hline Fate cause & \multicolumn{2}{|c|}{ Parity 1} & \multicolumn{2}{|c|}{ Parity 2} & \multicolumn{2}{|c|}{ Parity 3} & \multicolumn{2}{|c|}{ Parity 4} & \multicolumn{2}{|c|}{ Parity $5+$} \\
\hline Bloat & 29.2 & 2 & 20.5 & 2 & 17.43 & 2 & 14.3 & 2 & 39.5 & 2 \\
\hline Calving trouble & 21.0 & 12 & 16.1 & 10 & 12.0 & 9 & 12.3 & 9 & 63.8 & 8 \\
\hline Culled for age & 4.3 & 93 & 4.5 & 92 & 5.5 & 93 & 7.9 & 94 & 355.9 & 97 \\
\hline Facial eczema & 12.1 & 60 & 12.1 & 60 & 10.7 & 59 & 9.6 & 58 & 31.2 & 56 \\
\hline Foot or leg problems & 15.6 & 81 & 9.9 & 82 & 10.9 & 86 & 13.5 & 86 & 115.1 & 91 \\
\hline Fertility & 5.0 & 100 & 5.9 & 100 & 5.7 & 100 & 6.2 & 100 & 54.7 & 100 \\
\hline Grass staggers & 1.4 & 15 & 1.6 & 14 & 1.7 & 10 & 1.9 & 7 & 7.4 & 5 \\
\hline High SCS & 10.9 & 100 & 11.8 & 100 & 16.1 & 100 & 23.2 & 100 & 208.4 & 100 \\
\hline Injury or accident & 28.9 & 20 & 20.4 & 19 & 17.9 & 20 & 16.9 & 21 & 70.6 & 26 \\
\hline Low production & 123.1 & 100 & 108.2 & 100 & 92.5 & 100 & 88.7 & 100 & 394.4 & 100 \\
\hline Sold for reasons unknown & 13.9 & 98 & 12.7 & 98 & 12.3 & 98 & 14.3 & 98 & 79.6 & 98 \\
\hline Temperament & 20.3 & 99 & 10.1 & 100 & 7.2 & 100 & 5.8 & 99 & 16.8 & 99 \\
\hline Traits other than production & 6.7 & 99 & 3.5 & 99 & 3.1 & 99 & 3.4 & 99 & 15.6 & 99 \\
\hline Udder problems & 49.4 & 99 & 31.7 & 99 & 36.0 & 99 & 41.5 & 99 & 194.8 & 99 \\
\hline Unknown & 370.5 & 75 & 300.2 & 75 & 274.7 & 75 & 293.5 & 76 & $1,513.4$ & 80 \\
\hline All & $1,161.2$ & 83 & 967.9 & 84 & 900.6 & 84 & 976.1 & 85 & $5,405.7$ & 88 \\
\hline
\end{tabular}

${ }^{1}$ Percentage of cows recorded with a fate type of culled and sent to slaughter for each parity is displayed; remaining percentage with a fate type of died on farm is not displayed.

tion loss, and value of genetic merit. Last, the model considered the stage of lactation during which cows exited the herd and whether the carcass salvage value was captured.

A model was developed to consider the parity during which cows exit and the consequent effect this had on the replacement rate and average age structure of the herd. At the core of this model was a set of simple Markov chain relationships denoting the survival of cows from one parity to the next based on mean survival probability parameters that match the age structure of a typical pasture-based herd (21\% in parity $1,18 \%$ in parity $2,14 \%$ in parity $3,13 \%$ in parity $4,10 \%$ in parity $5,8 \%$ in parity $6,6 \%$ in parity $7,4 \%$ in parity 8 , and $5 \%$ in parity $9+$; P. R. Amer, AbacusBio Ltd., Dunedin, New Zealand, unpublished data). The number of replacement heifers that entered the herd was derived from the Markov chain, such that herd size remained stable over time at $n=100$. The number of culled cows of each age generated by this equilibrium herd was calculated from mortality proportions $(1-$ survival probabilities from one age to the next) and then multiplied by the proportion of the herd in the preceding parity. The structure and detail of this model has been used in another context of calculating economic values for survival traits to weight genetic traits in selection indexes (Amer et al., 2001, 2014).
To determine the long-term effect of a cow exiting at a certain parity, the survival probability of that parity was adjusted upward by 0.01 (one parity at a time). This resulted in a change of all successive parity transitions. To ensure that a herd size was maintained at $\mathrm{n}=100$, the model derived the new number of replacements required and altered the age structure of the herd. An important aspect of this model is that it captures the real-world attribute of fewer replacements being required when an older cow exits the herd. This is because when an older cow exits, the long-term effect is not one full replacement because the cow had at most only a few parities left that require replacement. The number of replacements required when a cow exits at a certain parity are presented in Table 3.

The model then considered the effect of cows exiting at different parities on the average age structure of the herd and the effect this had on replacement cost, cull salvage value, milk production loss, and value of genetic merit (Table 3). These estimates of costs and benefits were derived from the New Zealand national breeding objective economic model (P. R. Amer, unpublished data).

The replacement cost of a cow before its first calving was estimated to be NZ\$1,445 (NZ\$1 = US $\$ 0.69)$. This was based on the sum of costs to rear a replacement from a newborn calf to $40 \mathrm{wk}$ of age [rearing costs $(\mathrm{NZ} \$ 187$ / 
calf), grazing costs (32 wk at NZ\$6/wk), animal health costs (NZ $\$ 10 /$ animal), and animal losses $(2 \%)]$, from $40 \mathrm{wk}$ to $1 \mathrm{yr}$ and $40 \mathrm{wk}$ of age [grazing costs (52 wk at $\mathrm{NZ} \$ 9 / \mathrm{wk}$ ), animal health and reproduction (NZ\$50/ cow), and animal losses (2\%)], and from $1 \mathrm{yr}$ and 40 wk to $2 \mathrm{yr}$ of age [grazing costs (13 wk at NZ $\$ 24 /$ wk), animal health (NZ\$20/cow), and animal losses (2\%)].

To estimate expected revenue from carcass salvage, the average carcass weight was estimated for each parity and multiplied by a carcass price of NZ $\$ 3.03 / \mathrm{kg}$ of carcass. The carcass weight for each parity was estimated by multiplying the average live weight, weighted across breed (Holstein Friesian, Jersey, and Friesian crossJersey), by a dressing percentage of $44 \%$. The average live weight, weighted across breed, for parities 1, 2, 3, and $4+$ was $374,440,467$, and $480 \mathrm{~kg}$, respectively.

The cost in production loss due to younger cows entering the herd was estimated by calculating the expected profit difference for a cow of parity 1,2 , or 3 relative to that for a cow of parity $4+$. Milk revenue differences for a cow of parity 1,2, or 3 relative to those for a cow of parity $4+$ were estimated by subtracting the average milk solid (MS; milk fat + protein) production for cows of parity 1,2 , or 3 from the average MS production for cows of parity $4+$ and multiplying the difference by an average milk price of $\$ 7.03 / \mathrm{kg}$ of MS. The average MS production, weighted by breed (Holstein Friesian, Jersey, and Friesian cross-Jersey), for parities 1, 2, 3, and 4+ was assumed to be 276, 325,356 , and $370 \mathrm{~kg}$ of MS, respectively. Feed cost differences for a cow of parity 1, 2, or 3 relative to a cow of parity $4+$ were estimated by subtracting the average energy requirements for maintenance, growth, and lactation for cows of parity 1, 2, or 3 from the average energy requirements for maintenance, growth, and lactation for cows of parity $4+$ and multiplying the difference by an average feed cost of $\$ 0.03 / \mathrm{MJ}$ of ME. The average energy requirements for maintenance, growth, and lactation, respectively, weighted by breed (Holstein Friesian, Jersey, and Friesian cross-Jersey) were $13,450,2,794$, and $20,628 \mathrm{MJ}$ of $\mathrm{ME} /$ lactation for parity $1 ; 14,589,1,142$, and 24,339 MJ of ME/lactation for parity $2 ; 15,181,0$, and 27,744 MJ of ME/lactation for parity 3; and 15,181, 0, and 27,763 MJ of ME/ lactation for parity $4+$. The change in genetic merit was based on an industry genetic trend of $\$ N Z 10 / y r$.

The associated costs and benefits were quantified according to the stage of lactation during which the cow was removed and whether the farmer could capture the carcass salvage value (i.e., culled and sent to slaughter or died on farm; Table 4). Depending on stage of lactation, assumptions were made regarding the amount and cost of health treatments and whether they were applied by the farmer or vet (Table 4). Assumptions were also made about the proportion of wintering costs that would be recovered if the following lactation was not complete; 0, 20, 50, 100, and $25 \%$ of wintering costs were recovered for beginning (0-30 DIM), early (30-90 DIM), mid (90-200 DIM), late (200-330 DIM), or extreme (330+ DIM) lactations, respectively (Peter O'Neill, AbacusBio Ltd., Dunedin, New Zealand, personal communication). Wintering costs per cow were assumed to be $\mathrm{NZ} \$ 280$ ( $\$ 28 / \mathrm{wk}$ for $10 \mathrm{wk}$ based on typical contract grazing rates; Peter O'Neill, personal communication). It was also assumed that when cows exit the herd earlier in lactation there would be no effect on total milk production. This was based on the assumption that the feed not consumed by the cow that had exited would be readily available to cows remaining in the herd (Peter O'Neill, personal communication).

Table 3. Costs of wastage per cow across different parities (1-9+)

\begin{tabular}{|c|c|c|c|c|c|c|c|}
\hline \multirow[b]{2}{*}{ Parity } & \multirow{2}{*}{$\begin{array}{l}\text { Net } \\
\text { replacement } \\
\text { required }(\%)\end{array}$} & \multicolumn{5}{|c|}{ Culled and sent for slaughter } & \multirow{2}{*}{$\begin{array}{c}\text { Died on farm } \\
\begin{array}{c}\Sigma \text { costs } / \text { cow } \\
\text { lost }(\mathrm{NZ} \$)\end{array}\end{array}$} \\
\hline & & $\begin{array}{l}\text { Replacement } \\
\text { cost }^{1}(\mathrm{NZ} \$)\end{array}$ & $\begin{array}{c}\text { Carcass salvage }^{2} \\
(\mathrm{NZ} \$)\end{array}$ & $\begin{array}{l}\text { Production } \\
\operatorname{loss}^{3}(\mathrm{NZ} \$)\end{array}$ & $\begin{array}{l}\text { BW }_{\text {change }}^{4} \\
(\mathrm{NZ} \$)\end{array}$ & $\begin{array}{l}\sum \text { costs } / \text { cow } \\
\text { lost }(\mathrm{NZ} \$)\end{array}$ & \\
\hline 1 & 0.93 & $1,308.55$ & -436.43 & 400.01 & -32.51 & $1,239.63$ & $1,741.18$ \\
\hline 2 & 0.89 & $1,258.61$ & -492.73 & 588.94 & -62.31 & $1,292.52$ & $1,882.88$ \\
\hline 3 & 0.76 & $1,074.18$ & -446.49 & 557.59 & -78.26 & $1,107.01$ & $1,733.00$ \\
\hline 4 & 0.72 & $1,014.08$ & -438.23 & 526.40 & -99.44 & $1,002.80$ & $1,646.60$ \\
\hline 5 & 0.64 & 898.86 & -388.44 & 466.59 & -109.71 & 867.29 & $1,511.09$ \\
\hline 6 & 0.55 & 779.70 & -336.95 & 404.73 & -113.93 & 733.55 & $1,377.35$ \\
\hline 7 & 0.46 & 654.98 & -283.05 & 339.99 & -111.68 & 600.25 & $1,244.05$ \\
\hline 8 & 0.42 & 590.23 & -255.07 & 306.38 & -115.70 & 525.85 & $1,169.64$ \\
\hline $9+$ & 0.34 & 482.03 & -208.31 & 250.22 & -105.71 & 418.23 & $1,062.03$ \\
\hline
\end{tabular}

${ }^{1} \mathrm{NZ} \$ 1,415 /$ replacement $(\mathrm{NZ} \$ 1=\mathrm{US} \$ 0.69)$.

${ }^{2} \mathrm{NZ} \$ 3.03 / \mathrm{kg}$ of carcass live weight per dressing percentage.

${ }^{3}$ Milk solid revenue - feed cost; NZ $\$ 7.03 / \mathrm{kg}$ of milk solids; NZ\$0.03/MJ of ME.

${ }^{4} \mathrm{NZ} \$ 10 / \mathrm{yr}$. 
Table 4. Percentages of cows by fate reason group that were recorded to be culled and sent to slaughter (as opposed to those that died on farm) either during beginning (0-30 DIM) or early (30-90 DIM) lactation or during mid (90-200 DIM), late (200-330 DIM), or extreme (330+ DIM) lactation as well as the percentage of cows that were assumed to be treated by vet or farmer and the associated cost per treatment ${ }^{1}$

\begin{tabular}{|c|c|c|c|c|c|c|}
\hline Fate reason & \multicolumn{2}{|c|}{ Culled (\%) } & \multicolumn{2}{|r|}{ Treated by vet } & \multicolumn{2}{|c|}{ Treated by farmer } \\
\hline Bloat & 1 & 3 & 0 & - & 100 & 30 \\
\hline Calving trouble & 8 & 16 & 50 & 600 & 50 & 150 \\
\hline Culled for age & 80 & 98 & 0 & - & 0 & - \\
\hline Facial eczema & 48 & 61 & 50 & 50 & 50 & 25 \\
\hline Foot or leg problems & 74 & 92 & 50 & 165 & 50 & 55 \\
\hline Fertility & 95 & 100 & 100 & 100 & 0 & 25 \\
\hline Grass staggers & 2 & 18 & 20 & 165 & 80 & 55 \\
\hline High SCS & 99 & 100 & 0 & - & 100 & 80 \\
\hline Injury or accident & 18 & 25 & 50 & 165 & 50 & 55 \\
\hline Low production & 100 & 100 & 0 & - & 0 & - \\
\hline Sold for reasons unknown & 97 & 98 & 0 & - & 0 & - \\
\hline Temperament & 99 & 100 & 0 & - & 100 & 50 \\
\hline Traits other than production & 97 & 99 & 0 & - & 100 & 50 \\
\hline Udder problems & 98 & 100 & 0 & - & 100 & 50 \\
\hline Unknown & 42 & 85 & 0 & - & 0 & - \\
\hline
\end{tabular}

${ }^{1} \mathrm{NZ} \$ 1=\mathrm{US} \$ 0.69$

The equation used to identify the cost of culling $C_{i j k}$ for the $i$ th wastage reason for a cow of the $j$ th parity in stage of lactation $k$ was

$C_{i j k}=\rho_{i k}^{\text {cull }} \times V_{j}^{\text {cull }}+\left(1-\rho_{i k}^{\text {cull }}\right) \times\left(V_{j}^{\text {dead }}+V^{\text {disp }}\right)+\rho_{i}^{\text {vet }} \times V_{i}^{\text {vet }}$

$+\rho_{i}^{\text {farm }} \times V_{i}^{\text {farm }}+V_{k}^{\text {wint }}$,

where $\rho_{i k}^{\text {cull }}$ is the proportion of animals with wastage reason $i$ at stage of lactation $k$ that are culled as opposed to dying on farm; $V_{j}^{\text {cull }}$ is the cost of replacing a cow of parity $j$ after deducting its carcass salvage value obtained at slaughter; $V_{j}^{\text {dead }}$ is the cost of replacing a cow of parity $j$ with no salvage value because the cow died on farm; $V^{\text {disp }}$ is the cost of disposing of a cow that died on farm; $\rho_{i}^{\text {vet }}$ is the proportion of cows with wastage reason $i$ treated by a veterinarian; $V_{i}^{v e t}$ is the cost associated with veterinarian treatment for wastage reason $i ; \rho_{i}^{f a r m}$ is the proportion of the cows with wastage reason $i$ treated by a farmer; $V_{i}^{\text {farm }}$ is the cost associated with farmer treatment for wastage reason $i$; and $V_{k}^{\text {wint }}$ is the cost of proportion of unrecovered wintering cost at stage of lactation $k$.

The following is an example of how the cost of culling is calculated for calving trouble for a first-parity cow in the beginning stage of lactation:

$$
\begin{aligned}
& \mathrm{NZ} \$ 2,450\left(C_{i j k}\right)=0.08\left(\rho_{i k}^{\text {cull }}\right) \times \mathrm{NZ} \$ 1,240\left(V_{j}^{\text {cull }}\right) \\
& +\left[1-0.92\left(\rho_{i k}^{\text {cull }}\right)\right] \times\left[\mathrm{NZ} \$ 1,741\left(V_{j}^{\text {dead }}\right)+\mathrm{NZ} \$ 100\left(V^{\text {disp }}\right)\right] \\
& +0.5\left(\rho_{i}^{\text {vet }}\right) \times \mathrm{NZ} \$ 600\left(V_{i}^{\text {vet }}\right)+0.5\left(\rho_{i}^{\text {farm }}\right) \times \mathrm{NZ} \$ 150\left(V_{i}^{\text {farm }}\right) \\
& +\mathrm{NZ} \$ 280\left(V_{k}^{\text {wint }}\right)
\end{aligned}
$$

where $\rho_{i k}^{\text {cull }}$ is the $8 \%$ of animals with calving trouble at the beginning stage of lactation that were culled as opposed to dying on farm (Table 4$) ; V_{j}^{\text {cull }}$ is the cost of replacing a cow of parity 1 after deducting its carcass salvage value obtained at slaughter (Table 3 ); $V_{j}^{\text {dead }}$ is the cost of replacing a cow of parity 1 with no salvage value because the cow died on farm (Table 3 ); $V^{\text {disp }}$ is the cost of disposing of a cow that died on farm $(\$ N Z 100) ; \rho_{i}^{v e t}$ is the proportion of cows culled due to calving trouble that were treated by the veterinarian (Table 4$) ; V_{i}^{v e t}$ is the cost associated with veterinarian treatment for calving trouble (Table 4 ); $\rho_{i}^{\text {farm }}$ is the proportion of the cows culled due to calving trouble that were treated by the farmer (Table 4 ); $V_{i}^{\text {farm }}$ is the cost associated with farmer treatment for calving trouble (Table 4); and $V_{k}^{\text {wint }}$ is the cost of unrecovered wintering cost at the beginning of lactation ( $\mathrm{NZ} \$ 280)$. 
Note that the average cost per cow for calving trouble is NZ\$2,208 in Table 6. This was calculated as a weighted average across parities and stage of lactation and therefore is different from the calculated value of $\mathrm{NZ} \$ 2,450$ in this example.

\section{RESULTS}

\section{Reasons and Timing of Cow Wastage}

The most common reasons recorded for wastage were nonpregnancy, unknown, low production, culled for age, udder problems, mastitis, high SCS, foot or leg problems, disease, and injury or accident (Table 5). Nonpregnant, unknown, and low production accounted for $71 \%$ of wastage, with the remaining $29 \%$ due to reasons that individually accounted for less than $5 \%$ of the total (Table 5). When reasons for cow wastage were classified into broad categories, $56 \%$ of the total records were classified as reproductive, health, other, and physical reasons; $15 \%$ as performance and management reasons; and 29\% as unknown reasons (Table 1). Within the biological (reproduction, health, other, and physical) reasons, the 10 most common reasons for wastage were nonpregnant, udder problems, mastitis, high SCS, foot or leg problems, disease, injury or accident, calving trouble, bloat, and milk fever (Table 5). Although it is difficult to understand the exact reasons for the unknown wastage category, we do understand what parity and stage of lactation these cows are in when they exit the herd. Results show that $55 \%$ of these cows exit in parity $5+$ and that across all parities 75 to $80 \%$ are culled and sent to slaughter. Understanding this pattern allows us to estimate cost without knowing the exact reason for exit.

\section{Estimated Cost for Different Wastage Reasons at the Cow and Industry Levels}

The costs of recorded wastage on a per-cow and total industry basis are presented in Table 6 . The 10 costliest reasons per cow case were calving trouble, bloat, grass staggers, milk fever, hypomagnesemia, injury or accident, other metabolic disorders, other known fates, disease, and facial eczema.

The total wastage cost at an industry level was estimated to be NZ $\$ 23,628 / 100$ cows per year. The 10 costliest wastage reasons to industry were nonpregnant, unknown, low production, mastitis, udder problems, culled for age, calving trouble, injury or accident, high SCS, and disease (Table 6). The empty and unknown fate causes accounted for NZ\$7,279 and NZ\$7,021 per 100 cows, respectively, whereas low production, mastitis, and udder problems accounted for a further
NZ $\$ 1,817, \mathrm{NZ} \$ 992$, and NZ $\$ 823$ per 100 cows, respectively (Table 6).

\section{DISCUSSION}

The total cost of cow wastage in a pasture-based dairy industry was estimated to be $\mathrm{NZ} \$ 23,628 / 100$ cows per year. Approximately $60 \%$ ( $\$ 14,300 / 100$ cows) of total costs were attributed to cow removals due to

Table 5. The 10 main reasons for wastage and total costs and the 10 main reasons for biological (reproductive, health, other, and physical) wastage and total costs

\begin{tabular}{|c|c|c|}
\hline Rank & Main reasons for wastage ${ }^{1}$ & $\%$ \\
\hline \multicolumn{3}{|c|}{ Frequency } \\
\hline 1 & Nonpregnant & 33 \\
\hline 2 & Unknown & 29 \\
\hline 3 & Low production & 9 \\
\hline 4 & Culled for age & 4 \\
\hline 5 & Udder problems & 4 \\
\hline 6 & Mastitis & 4 \\
\hline 7 & High SCS & 3 \\
\hline 8 & Foot or leg problems & 2 \\
\hline 9 & Disease & 2 \\
\hline 10 & Injury or accident & 2 \\
\hline \multicolumn{3}{|c|}{ As proportion of total cost } \\
\hline 1 & Nonpregnant & 31 \\
\hline 2 & Unknown & 30 \\
\hline 3 & Low production & 8 \\
\hline 4 & Mastitis & 4 \\
\hline 5 & Udder problems & 3 \\
\hline 6 & Culled for age & 3 \\
\hline 7 & Calving trouble & 3 \\
\hline 8 & Injury or accident & 3 \\
\hline 9 & High SCS & 2 \\
\hline 10 & Disease & 2 \\
\hline Rank & Biological reasons for wastage ${ }^{2}$ & $\%$ \\
\hline \multicolumn{3}{|c|}{ Frequency } \\
\hline 1 & Nonpregnant & 60 \\
\hline 2 & Udder problems & 7 \\
\hline 3 & Mastitis & 7 \\
\hline 4 & High SCS & 5 \\
\hline 5 & Foot or leg problems & 3 \\
\hline 6 & Disease & 3 \\
\hline 7 & Injury or accident & 3 \\
\hline 8 & Calving trouble & 2 \\
\hline 9 & Bloat & 2 \\
\hline 10 & Milk fever & 2 \\
\hline \multicolumn{3}{|c|}{ As proportion of total costs } \\
\hline 1 & Nonpregnant & 54 \\
\hline 2 & Mastitis & 7 \\
\hline 3 & Udder problems & 6 \\
\hline 4 & Calving trouble & 4 \\
\hline 5 & Injury or accident & 4 \\
\hline 6 & High SCS & 4 \\
\hline 7 & Disease & 4 \\
\hline 8 & Bloat & 3 \\
\hline 9 & Foot or leg problems & 3 \\
\hline 10 & Milk fever & 3 \\
\hline
\end{tabular}

${ }^{1}$ Cows that were recorded by the farmer as died on farm or culled and sent to slaughter.

${ }^{2}$ Excludes unknown reasons. 
nonpregnant and unknown reasons, with another $15 \%$ $(\$ 3,631 / 100$ cows $)$ attributed to low production, mastitis, and udder problems. Total costs were driven by the proportion of animal wastage and the cost per cow for each reason. Reproductive failure was the primary cause of cow wastage. However, it was closely followed by removal for unknown reasons, with considerably fewer animals removed due to low milk production, old age, udder problems, or mastitis. Reproductive failure, low production, mastitis, and udder problems have been reported as common reasons for culling in other studies (Seegers et al., 1998; Hadley et al., 2006; Maher et al., 2008; Pinedo et al., 2010). Although removals in the current study were within the ranges reported for reproductive failure and low production (18-36\% and $5-16 \%$ of culls, respectively), they were generally lower than the removal rates previously reported for mastitis and udder problems (8-12\% and $3-8 \%$ of culls, respectively). It is also interesting to note that the reasons for culling in the current study were also reported as common reasons for dairy systems in Europe (Seegers et al., 1998) and America (Hadley et al., 2006; Pinedo et al., 2010). This suggests that the wastage reasons reported in the current study are not necessarily a specific issue for seasonal pasture-based systems but rather are a wider industry issue.
The costs of wastage per animal vary across the different cow wastage reasons. Calving trouble, bloat, grass staggers, milk fever, hypomagnesemia, injury or accident, other metabolic disorders, and other known reasons were 1.5 to 2 times costlier per cow than all other wastage reasons. These differences were driven primarily by the parity during which the wastage occurred and whether the cow was culled and sent for slaughter or died on farm. This is because when an animal exits at an early parity, the replacement cost associated with that animal cannot be recovered. Likewise, when a death occurs on farm, the value of the carcass cannot be obtained. These drivers of differences in cost per cow have been noted by others (Lehenbauer and Oltjen, 1998; Orpin and Esslemont, 2010; Orpin and Sibley, 2014). At an industry level, wastage reasons that cost more per cow can increase in relative importance as opposed to rankings based on incidence alone. In our analysis, however, the rankings of various wastage reasons remained unchanged when costed on a per-animal or total industry basis. Due to the risk of misclassification of farmer-recorded reasons (McConnel et al., 2009; Thomsen et al., 2012) and the large amount of "unknown" and missing data, a certain level of caution is still required with this analysis. Future research could focus on filtering industry data for herds

Table 6. Total annual industry costs associated with cows that were recorded as culled and sent to slaughter or died on farm for different wastage reasons in New Zealand ${ }^{1}$

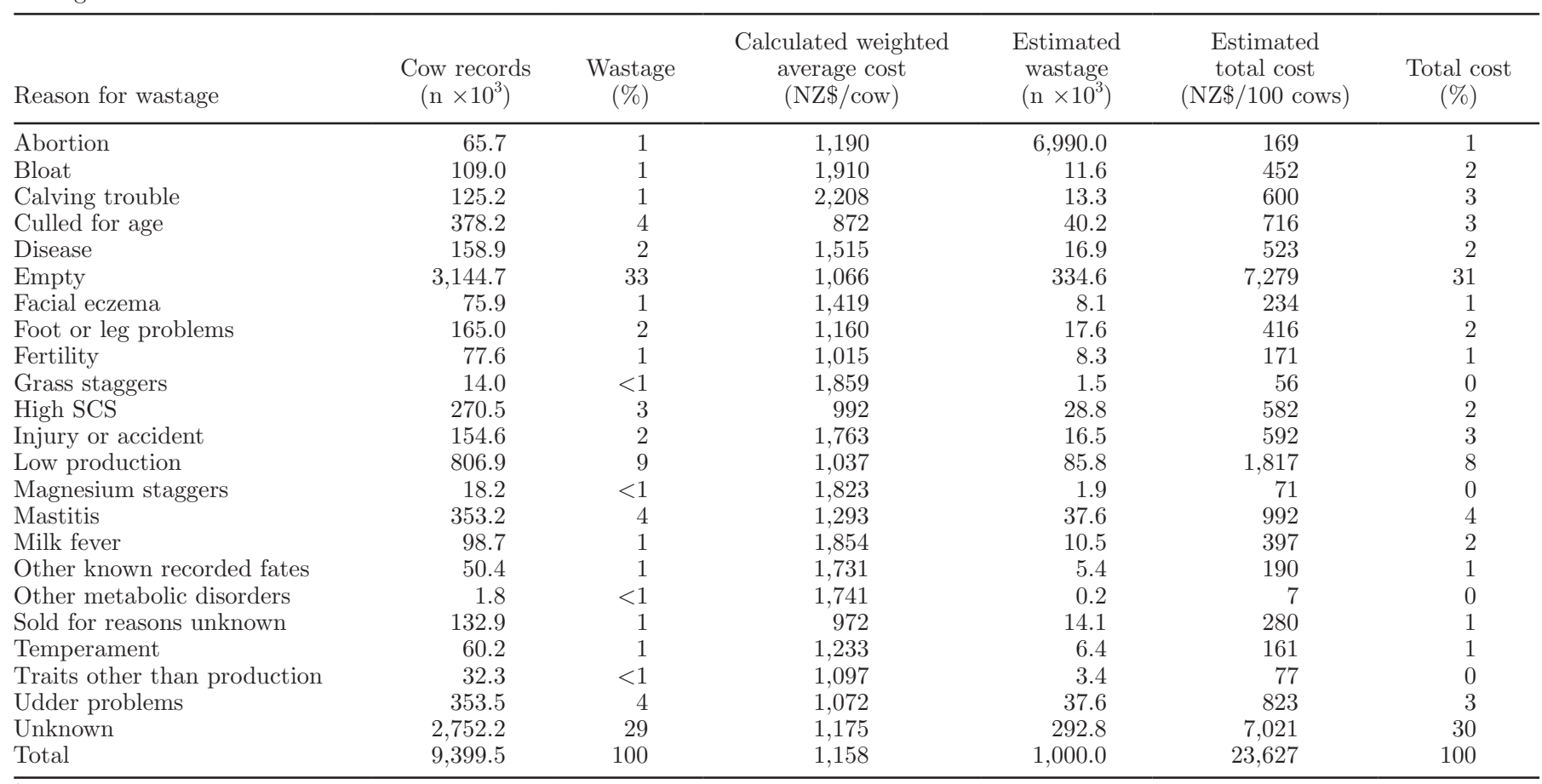

${ }^{1} \mathrm{NZ} \$ 1=\mathrm{US} \$ 0.69$ 
with poor survival but high data recording accuracy to determine whether there are any noticeable differences in relative incidences of reasons for wastage.

The development of effective herd health and production management programs that target improvements in the underlying causes of on-farm deaths and culling and the use of new criteria or traits that improve the accuracy of genetic selection (Egger-Danner et al., 2015) are key approaches to reducing cow wastage. For example, the use of calving season day, postpartum anestrous interval, and gestation length can increase the accuracy of prediction of fertility genetic merit (Bowley et al., 2015; Stachowicz et al., 2015), and the use of clinical mastitis data can improve the accuracy of prediction of mastitis resistance (Heringstad et al., 2000; Odegård et al., 2003; Jury, 2011). The main challenge moving forward will be the cost-effective collection of sufficient levels of data (Pryce et al., 1997; EggerDanner et al., 2015). The current large percentage of unknown recorded reasons and lack of reliable data for fertility and health traits could be overcome with further research into (1) understanding farmer motivation for recording data and what short-and long-term outcomes would add value to their business (Pryce et al., 1997), (2) the use of automatic data collection and sensing technologies to ensure that data capture is easy and cost effective (Rutten et al., 2013), and (3) the use of information herds to collect high-cost novel criteria for genotyping (Egger-Danner et al., 2015). The first 2 points would also contribute to the development of herd health and production management programs, whose effectiveness is reliant on the ability to accurately define and quantify potential issues, a clear understanding of associated risk factors and what is regulating occurrence, and a cost-effective plan to intervene (McDougall et al., 2014).

In summary, wastage costs NZ $\$ 23,628 / 100$ cows per year in pasture-based systems; biological and potentially avoidable reasons cost a total of NZ $\$ 13,555 / 100$ cows per year. There is a strong economic case for pasture-based dairy industries to invest in genetic and herd health and production management research focused on reducing animal wastage due to reproductive failure, mastitis, udder problems, injuries or accidents, and calving difficulties. A useful next step would be to quantify wastage, and the reasons for wastage, across herds within a pastoral system. An assessment of herdlevel factors contributing to wastage, and an understanding of the different levels of performance across herds, would provide us with a clearer picture of what factors could be addressed with current research and technologies and what areas may require new research. This benchmarking would also allow us to understand how much of the total wastage costs could be realistically saved.

\section{ACKNOWLEDGMENTS}

This work was funded by the Ministry of Business, Innovation and Employment and New Zealand dairy farmers through DairyNZ Inc. (Hamilton, New Zealand). We thank LIC (Hamilton, New Zealand) for downloading and supplying the data set from the New Zealand Dairy Core Database for the purposes of this study.

\section{REFERENCES}

Amer, P. R., C. I. Ludemann, and S. Hermesch. 2014. Economic weights for maternal traits of sows, including sow longevity. J. Anim. Sci. 92:5345-5357.

Amer, P. R., G. Simm, M. G. Keane, M. G. Diskin, and B. W. Wickham. 2001. Breeding objectives for beef cattle in Ireland. Livest. Prod. Sci. 67:223-239.

Bach, A. 2011. Associations between several aspects of heifer development and dairy cow survivability to second lactation. J. Dairy Sci. 94:1052-1057.

Beaudeau, F., V. Ducrocq, C. Fourichon, and H. Seegers. 1995. Effect of disease on length of productive life of French Holstein dairy cows assessed by survival analysis. J. Dairy Sci. 78:103-117.

Beaudeau, F., H. Seegers, V. Ducrocq, C. Fourichon, and N. Bareille. 2000. Effect of health disorders on culling in dairy cows: A review and a critical discussion. Ann. Zootech. 49:293-311.

Beaudeau, F., J. D. van der Ploeg, B. Boileau, H. Seegers, and J. P. T. M. Noordhuizen. 1996. Relationships between culling criteria in dairy herds and farmers' management styles. Prev. Vet. Med. 25:327-342.

Beukes, P. C., P. Gregorini, A. J. Romera, G. Levy, and G. C. Waghorn. 2010. Improving production efficiency as a strategy to mitigate greenhouse gas emissions on pastoral dairy farms in New Zealand. Agric. Ecosyst. Environ. 136:358-365.

Bowley, F. E., R. E. Green, P. R. Amer, and S. Meier. 2015. Novel approaches to genetic analysis of fertility traits in New Zealand dairy cattle. J. Dairy Sci. 98:2005-2012.

de Vries, M., E. M. Bokkers, G. van Schaik, B. Engel, T. Dijkstra, and I. J. M. de Boer. 2014. Exploring the value of routinely collected herd data for estimating dairy cattle welfare. J. Dairy Sci. 97:715-730.

Egger-Danner, C., J. B. Cole, J. E. Pryce, N. Gengler, B. Heringstad, A. Bradley, and K. F. Stock. 2015. Invited review: Overview of new traits and phenotyping strategies in dairy cattle with a focus on functional traits. Animal 9:191-207.

Fourichon, C., H. Seegers, N. Bareille, and F. Beaudeau. 1999. Effects of disease on milk production in the dairy cow: A review. Prev. Vet. Med. 41:1-35.

Hadley, G. L., C. A. Wolf, and S. B. Harsh. 2006. Dairy cattle culling patterns, explanations, and implications. J. Dairy Sci. 89:22862296.

Heringstad, B., G. Klemetsdal, and J. Ruane. 2000. Selection for mastitis resistance in dairy cattle: A review with focus on the situation in the Nordic countries. Livest. Prod. Sci. 64:95-106.

Horan, B., P. Dillon, D. P. Berry, P. O'Connor, and M. Rath. 2005. The effect of strain of Holstein-Friesian, feeding system and parity on lactation curves characteristics of spring-calving dairy cows. Livest. Prod. Sci. 95:231-241.

Jury, K. E. 2011. Genetic analysis of incidence of clinical mastitis in New Zealand dairy cattle. MS Thesis. Maasey University, Palmerston North, New Zealand. 
Lehenbauer, T. W., and J. W. Oltjen. 1998. Dairy cow culling strategies: Making economical culling decisions. J. Dairy Sci. 81:264-271.

Maher, P., M. Good, and S. J. More. 2008. Trends in cow numbers and culling rate in the Irish cattle population, 2003 to 2006. Ir. Vet. J. $61: 455-463$.

McConnel, C. S., F. B. Garry, J. E. Lombard, J. A. Kidd, A. E. Hill, and D. H. Gould. 2009. A necropsy-based descriptive study of dairy cow deaths on a Colorado dairy. J. Dairy Sci. 92:1954-1962.

McDougall, S., C. Heuer, J. Morton, and T. Brownlie. 2014. Use of herd management programmes to improve the reproductive performance of dairy cattle. Animal 8:199-210.

Mohd Nor, N., W. Steeneveld, M. C. M. Mourits, and H. Hogeveen. 2015. The optimal number of heifer calves to be reared as dairy replacements. J. Dairy Sci. 98:861-871.

Mulligan, F. J., and M. L. Doherty. 2008. Production diseases of the transition cow. Vet. J. 176:3-9.

Mulligan, F. J., L. O'Grady, D. A. Rice, and M. L. Doherty. 2006. A herd health approach to dairy cow nutrition and production diseases of the transition cow. Anim. Reprod. Sci. 96:331-353.

Odegård, J., G. Klemetsdal, and B. Heringstad. 2003. Genetic improvement of mastitis resistance: Validation of somatic cell score and clinical mastitis as selection criteria. J. Dairy Sci. 86:41294136.

Oltenacu, P. A., and B. O. Algers. 2005. Selection for increased production and the welfare of dairy cows: Are new breeding goals needed? Ambio 34:311-315.

Oltenacu, P. A., and D. M. Broom. 2010. The impact of genetic selection for increased milk yield on the welfare of dairy cows. Anim. Welf. 19:39-49.

Orpin, P. G., and R. J. Esslemont. 2010. Culling and wastage in dairy herds: An update on incidence and economic impact in dairy herds in the UK. Cattle Pract. 18:163-172.
Orpin, P. G., and R. J. Sibley. 2014. Counting the culls and costing the casualties - Not all cull cows are the same. Cattle Pract. 22:200-205.

Pinedo, P. J., A. De Vries, and D. W. Webb. 2010. Dynamics of culling risk with disposal codes reported by Dairy Herd Improvement dairy herds. J. Dairy Sci. 93:2250-2261.

Pritchard, T., M. Coffey, R. Mrode, and E. Wall. 2012. Genetic parameters for production, health, fertility and longevity traits in dairy cows. Animal 7:34-46.

Pryce, J. E., R. F. Veerkamp, R. Thompson, W. G. Hill, and G. Simm. 1997. Genetic aspects of common health disorders and measures of fertility in Holstein Friesian dairy cattle. Anim. Sci. 65:353-360.

Rauw, W. M., E. Kanis, E. N. Noordhuizen-Stassen, and F. J. Grommers. 1998. Undesirable side effects of selection for high production efficiency in farm animals: A review. Livest. Prod. Sci. 56:15-33.

Rutten, C. J., A. G. J. Velthuis, W. Steeneveld, and H. Hogeveen. 2013. Invited review: Sensors to support health management on dairy farms. J. Dairy Sci. 96:1928-1952.

Seegers, H., F. Beaudeau, C. Fourichon, and N. Bareille. 1998. Reasons for culling French Holstein cows. Prev. Vet. Med. 36:257-271.

Stachowicz, K., G. M. Jenkin, P. R. Amer, J. R. Bryant, and S. Meier. 2015. Proposed changes in the genetic evaluation of dairy fertility in New Zealand. Proc. Assoc. Adv. Breed Genetics 21:370-373.

Thomsen, P. T., K. Dahl-Pedersen, and H. E. Jensen. 2012. Necropsy as a means to gain additional information about causes of dairy cow deaths. J. Dairy Sci. 95:5798-5803.

Walsh, S., F. Buckley, D. P. Berry, M. Rath, K. Pierce, N. Byrne, and P. Dillon. 2007. Effects of breed, feeding system, and parity on udder health and milking characteristics. J. Dairy Sci. 90:5767-5779. 